\title{
Review
}

\section{Development of Precise Pharmocodiagnostic (PharmDx) Tests for Molecular Targeted Therapies}

\author{
Yoichi Tani $^{1}$, Yutaka Hatanaka ${ }^{1}$ and Kaoru Hashizume ${ }^{1}$ \\ ${ }^{I}$ Department of Medical Science, DakoCytomation Co. Ltd., Kyoto, Japan
}

Received February 8, 2005; accepted February 8, 2005

Advanced biomolecular technologies have begun to provide beneficial means to detect a variety of cellular molecules for tumor diagnosis, as well as predictive and prognostic factors of cancers. This new understanding of the molecular basis of cancers has led to the development of molecular targeted approaches to cancer prevention and treatment. Molecules involved in the growth factor signaling system have become favored targets for molecular targeted therapies in translational research and clinical development. The current molecular targeting agents are classified into humanized or camera monoclonal antibodies and small-molecule tyrosine kinase inhibitors. Patients with HER2-overexpressing, metastatic breast cancer are beginning to benefit from the first commercially humanized monoclonal antibody (Herceptin), and the first small-molecule tyrosine kinase inhibitor (Gleevec/Glivec) has been introduced in Japan. Gleevec/ Glivec has been demonstrated to have a long-term clinical benefit for most refractory patients with Philadelphia chromosome-positive chronic myelogenous leukemia as well as with KIT-expressing, unresectable and/or metastatic gastrointestinal stromal tumor. Accurate and reliable HER2 or KIT testing is per- formed to determine patient eligibility for Herceptin or Gleevec/Glivec therapy, respectively.

HER1 (EGFR) and HER2 are the most widely studied target molecules for therapeutic inhibitions. HER family targeting has been initiated as the basis of extensive and growing drug development programs in various companies. A key technology of targeted therapies is molecular diagnosis with target identification. Along with the progressive development of HER-targeted therapies, the need to standardize immunohistochemical diagnostic tests for each targeted therapy is ever more pressing. Although the standardization of immunohistochemistry using archival formalin-fixed specimens is a tremendous challenge that will require great effort and considerable research, the development of an ideal pharmDx test for target molecular identification will be achieved by the optimal combination of heat-induced antigen retrieval with calcium-chelating solutions, effective signal amplification, and automated staining approaches. The expression levels and phosphorylation/ activation of various signaling molecules will be valuable in defining subpopulations of patients who may potentially respond to molecular targeted therapies.

Key words: humanized monoclonal antibody, small-molecule tyrosine kinase inhibitor, HER family, pharmDx, phosphorylated EGFR

Correspondence to: Yoichi Tani, Medical Science Department, DakoCytomation Co. Ltd., Hiraoka Building, Nishinotouin-higashiiru, Shijo-dori, Shimogyo-ku, Kyoto 600-8493, Japan.

E-mail: yoichi.tani@dakocytomation.jp 


\section{Introduction}

A new understanding of the important factors and signal transduction pathways that regulate cell growth, differentiation, and apoptosis has translated recent discoveries in cancer biology into novel approaches for the targeted therapies of cancers $[9,36,38,39]$. The targeted therapies approach yields distinctive potential therapeutic targets, and identifies subpopulations of patients who are most likely to benefit from new anti-cancer agents. Highly potential therapeutic targets have been found within the growth factor signaling system, and several growth factor receptors and their tyrosine kinase have become favored targets for monoclonal antibody-based and orally administered small-molecule therapies that are most advanced in clinical development or already available for use [3, 44, 50]. In Japan, patients with breast cancer, chronic myelogenous leukemia (CML), nonsmall cell lung cancer (NSCLC), and gastrointestinal stromal tumor (GIST) are beginning to benefit from molecular targeted therapies. The targeted therapies have heralded a promising era of hope for oncologists and patients, particularly in the treatment of solid tumors, cancers traditionally refractory to conventional chemotherapy and with poor prognosis.

A key technology for molecular targeted therapies will be molecular diagnosis with target molecular identification. Molecular or histochemical testing may help to identify predisposition to cancers, determine the onset of cancers for earlier intervention, and select the target for the most effective treatment. For the success of the targeted therapies, identification of patients bearing a target molecule, or activated target molecule is an absolute prerequisite for determining patient eligibility $[10,28,46,52]$. Progressive molecular biotechnologies based on immunohistochemistry (IHC) and in situ hybridization (ISH) techniques have provided a variety of beneficial means to identify tumor biology factors such as HER1 (EGFR), HER2, and KIT [17, 23, 47]. The application of diagnostic IHC is the most useful tool in molecular diagnosis as well as target identification for the molecular targeted therapies. Although IHC assay can be easily performed on routinely formalin-fixed, paraffinembedded (FFPE) specimens, the validity of IHC staining results depends upon tissue fixation, antigen-retrieval methods, and sensitivity of detection systems as well as systems for scoring and assessment of the staining. Therefore, IHC diagnostic tests for molecular targeted therapies, pharmacodiagnostic (pharmDx) tests, need to be standardized, considered in terms of their practicality and reproducibility, and also redesigned as a semiquantitative assay [19, 28, 46].

\section{Therapeutic Strategies to Target Molecules and Development of the Targeted Therapies}

Signal transduction researches have shown the importance of members of the human epidermal growth factor receptor (HER) family of transmembrane tyrosine kinase in a number of solid tumors [8, 24, 49, 51, 54]. HER2 is an important member of the HER family and frequently overexpressed or amplified in a number of tumor types [28, 46, 52]. HER2 overexpression or HER2 gene amplification is found in up to $30 \%$ of breast cancers, leading to aggressive behavior and an unfavorable prognosis. However, the overexpressed HER2 receptor protein also serves as a target for anti-HER2 humanized antibody therapy [43, 48].

In Japan, Herceptin was approved by the Ministry of Health, Labor, and Welfare (MHLW) in May 2001. Patients with metastatic breast cancer are beginning to benefit from this first commercially humanized monoclonal antibody, Herceptin. The likelihood of tumor regression with Herceptin therapy may be as high as 35 percent among patients with tumors that strongly overexpress HER2 [43]. The addition of chemotherapy enhances responses to the humanized antibody, and treatment of appropriately selected patients with Herceptin prolongs overall survival [4, 43]. Gleevec/ Glivec is one of the first of a new class of targeted anticancer agents introduced as a small-molecule tyrosine kinase inhibitor (TKI) that block the growth of Bcr-Abl transformed leukemic cells, and has demonstrated a long term clinical benefit for most refractory patients with Philadelphia chromosome-positive chronic myelogenous leukemia $\left(\mathrm{Ph}^{+} \mathrm{CML}\right)[11,12,22]$. After MHLW approval for $\mathrm{Ph}^{+} \mathrm{CML}$ in November 2001, Gleevec/Glivec has been also approved for the treatment of patients with unresectable and/or metastaic gastrointestinal stromal tumors (GISTs) in July 2003.

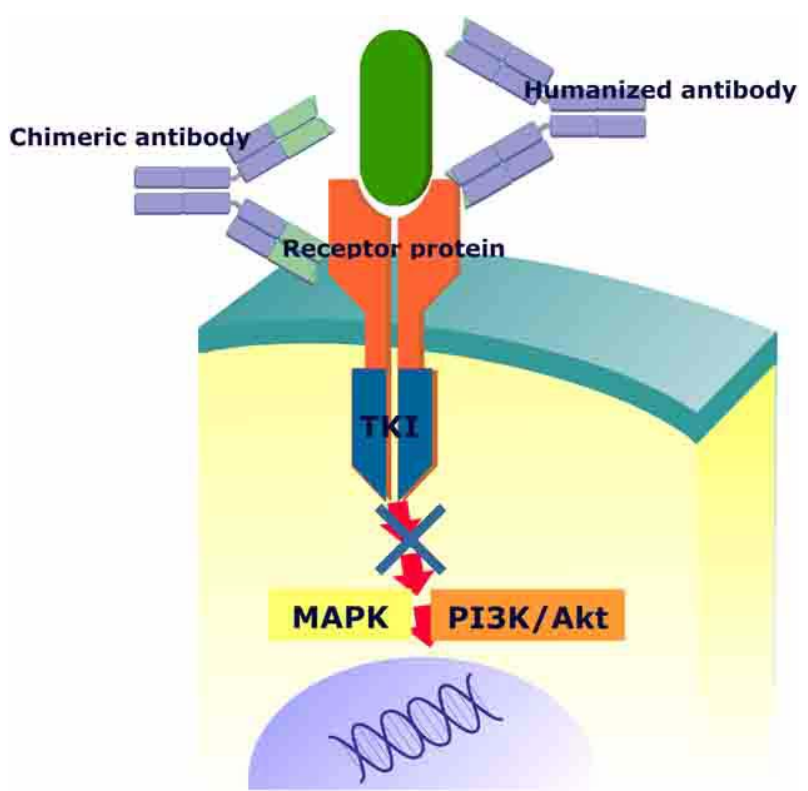

Fig. 1. Overview of strategies of molecular targeted therapies for growth factor receptors. While humanized or camera monoclonal antibodies (mABs) bind to the extracelluar portion of the targets, preventing activation or inducing antibody-dependent cell toxicity (ADCC), small-molecule tyrosine kinase inhibitors (TKIs) work by inhibiting the intracellular portion of the target molecules, thus blocking two main downstream signaling paths of PI3K/Akt and Ras/Raf/MAPK. 


\begin{tabular}{|c|c|c|c|}
\hline 2005 - 2007 & 2004-2006 & 2003-2004 & \\
\hline Phase I & Phase II & Phase III & Marketed \\
\hline GW-572016 & PKI-166 & Erlotinib HCl (Tarceva) & Trastsuzumab(Herceptin \\
\hline DualHER1/HER2 Reversible & Dual HER1/HER2 reversible & HER1 reversible TK & HER2 mAB \\
\hline TKI (GSK) & TKI & (Genentech/Roche/OSI) & (Genentech/Roche)) \\
\hline & (Norvartis) & & \\
\hline 2C4 HER2 mAB & TgDCC-EIA HER2 mAB & MDX-210 HER2 mAB & Gefitinib(Iressa) \\
\hline (Genentech) & (Targeted genetics) & (Medrex) & Reversible TKI \\
\hline & & & (AstraZeneca) \\
\hline & Canertinib(Cl-1033) & & Cetuximab(Erbitux) \\
\hline & Pan HER1-4 TKI & & HER1 mAB \\
\hline & (Pfizer) & & (Imclone/Merck) \\
\hline & EKB-569 & & \\
\hline & HER1/HER2 irreversible TKI & & \\
\hline & (Wyeth) & & \\
\hline & EMD-72000 HER1 mAB & & \\
\hline & (Merck KGaA) & & \\
\hline & ABX-EGF HER1 mAB & & \\
\hline & (Abgenix/Amgen) & & \\
\hline & h-R3 HER1 mAB & & \\
\hline & (York Medical) & & \\
\hline
\end{tabular}

Fig. 2. HER family targeted therapy in development.

Gleevec/Glivec has shrunk the tumors by half or more in most patients and stopped their growth in many other patients [23].

As represented by the above success stories of the targeted therapies by Herceptin and Gleevec/Glivec, the current molecular targeting therapeutic strategies are classified into the development of small-molecule TKIs, and humanized or camera monoclonal antibodies (mABs) [26, 39, 50]. Orally active TKIs are the most promising class of targeted agents currently in development, and work by inhibiting the intracellular portion of the target molecules, thus blocking downstream signaling. The injection of humanized and camera mABs was the earliest approach to targeting molecules, and the mABs worked by binding to the extracelluar portion of the targets, thus preventing activation or inducing antibody-dependent cell toxicity (ADCC) (Fig. 1).

HER1 (EGFR) and HER2 are the most widely studied HER family members. In many types of cancers, HER1 (EGFR) or HER2 expression is abnormal or upregulated, indicative of its possible role in tumorigenesis $[2,24,35$, 54]. Evidence suggests that HER1 (EGFR) and HER2 over- expression or dysregulation correlates with tumor progression, survival stage, and response to therapy, indicating it may be a potential target for therapeutic inhibition. Although the complexities of HER driven cell signaling have yet to be fully understood, several possible points for interruption of tumorigenic cellular mechanisms have been proposed [13, 32, 37]. HER1 (EGFR) and HER2 targeting have formed the basis of extensive and growing drug development programs in various companies (Fig. 2).

\section{Development of PharmDx Tests for Therapeutic Monoclonal Antibodies (mABs)}

Herceptin has already become a standard of care for HER2-overexpressing metastatic breast cancer and is prescribed in conjunction with a pharmDx test for HER2 protein overexpression or HER2 gene amplification. The presence or absence of overexpressed HER2 protein or HER2 gene amplification are used to differentiate patients who may have a response to the humanized antibody from 
those who do not have a response. Although several IHC based assays and only one FITC assay are available for determining eligibility for the Herceptin therapy, the FISH assay is not widespread in Japan due to practical and economical reasons [46, 52].

One of the pharmDx tests for HER2 expression, HercepTest, has been approved by MHLW as an in vitro diagnostic (IVD) kit in May 2001 when Herceptin was approved. It is an immunohistochemical staining system for semiquantitatively evaluating the expression status of HER2 proteins, and includes necessary antibodies and other reagents that have been optimized for detection of HER2 in FFPE specimens. Using the HercepTest scoring guidelines, the HER2 membrane staining is scored as $0,1+, 2+$, or $3+$ according to membrane-specific intensity and pattern continuity $[19,47]$. The conceptual IHC assay and scoring criteria have been taken over to EGFR pharmDx test as well [17]. EGFR pharmDx is already being used in Switzerland and USA to identify patients for Erbitux therapy. Erbitux, a camera monoclonal antibody against EGFR (HER1), has been used for treating irinotecan-refractory or intolerant metastatic, EGFR expressing colon cancer [17]. HercepTest and EGFR pharmDx may be straightforwardly utilized for other mABs as shown in Figure 2, by having them modify the definition of positive staining and negative staining of tumor cell as well as the threshold of \% positive cells [42].

In order to develop a pharmDx test for new $\mathrm{mAB}$ therapies, it is absolutely necessary to generate a very specific primary antibody against the same molecular target site as identified by the humanized or camera monoclonal antibodies. Simplification of the immunostaining procedure is one of the most important strategies to standardize the pharmDx test. Utilizing a simple dextran-polymeric detection system [55], a basic IHC assay for the therapeutic $\mathrm{mABs}$ is designed as presented in Figure 3. The basic assay is divided into as many as four steps, including antigen retrieval, endogenous peroxidase blocking, primary antibody reaction, and visualization with dextran-polymer reagents. The dextran-polymeric detection not only yields an intense signal of positive staining but also never induces the endogenous biotin activity that may be enhanced by heat-induced antigen retrieval techniques [7]. Although an enzymatic or heat-induced antigen retrieval procedure will have to be carefully selected and optimized according to the primary antibody used for the test [41], the endogenous peroxidase blocking and visualization procedures may be defined as standard steps in pharmDx tests for therapeutic mABs. The antigen retrieval technique may contribute to standardization of immunohistochemical staining of pharmDx tests, and result in increased robustness and sensitivity of the tests without compromising specificity in combination with an optimally diluted primary antibody. Additionally, while developing a prototyped pharmDx test for a new $\mathrm{mAB}$, the testing result must be evaluated and compared with the clinical response to the $\mathrm{mAB}$-based therapy in order to gain clinical accuracy and reliability of the pharmDX test as a prerequisite for determining patient eligibility [17, 46, 47].

\section{Development of PharmDx Tests for Tyrosine Kinase Inhibitors (TKIs)}

HER1 (EGFR) TKIs have transformative capacity in most common types of solid tumors and across tumor stages [32]. The majority of NSCLC express HER1 (EGFR), and the efficacy of HER1 (EGFR) TKIs in preclinical researches together with their favorable toxicity profiles has led to their clinical development in NSCLC [5, 20, 53]. Tarceva and Iressa have shown promising activity in NSCLC as single agents in phase II trails [15, 34]. However, randomized phase III studies of Tarceva or Iressa in combination with chemotherapy failed to demonstrate an increase in efficacy of HER1 (EGFR) TKIs over chemotherapy [16, 21]. The patients in these trails were enrolled regardless of EGFR expression levels in their tumors with strategy based on the high frequency of EGFR expression in NSCLC (up to 80\%). In contrast to HER2 testing for Herceptin, HER1 (EGFR) expression or overexpression does not predict for sensitivity to TKIs in tumor tissues from patients, hence there has been no appropriate target molecular testing for patients selection using tumor specimens.

The identification of potential responder to HER1

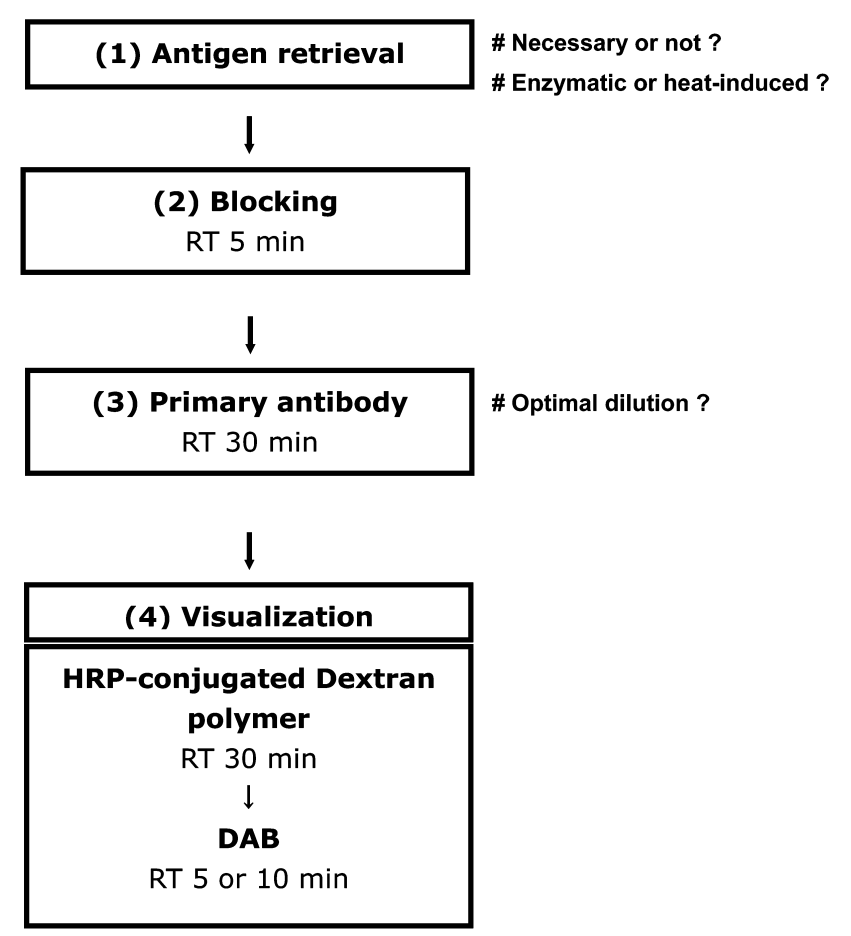

Fig. 3. Summary of a basic IHC assay for pharmDx test. A basic IHC based on the dextran-polymeric detection is divided into four steps, including antigen retrieval, endogenous peroxidase blocking, primary antibody reaction, and visualization with dextran-polymer reagents. An enzymatic or heat-induced antigen retrieval procedure will have to be carefully selected and optimized according to the primary antibody used for the test. 

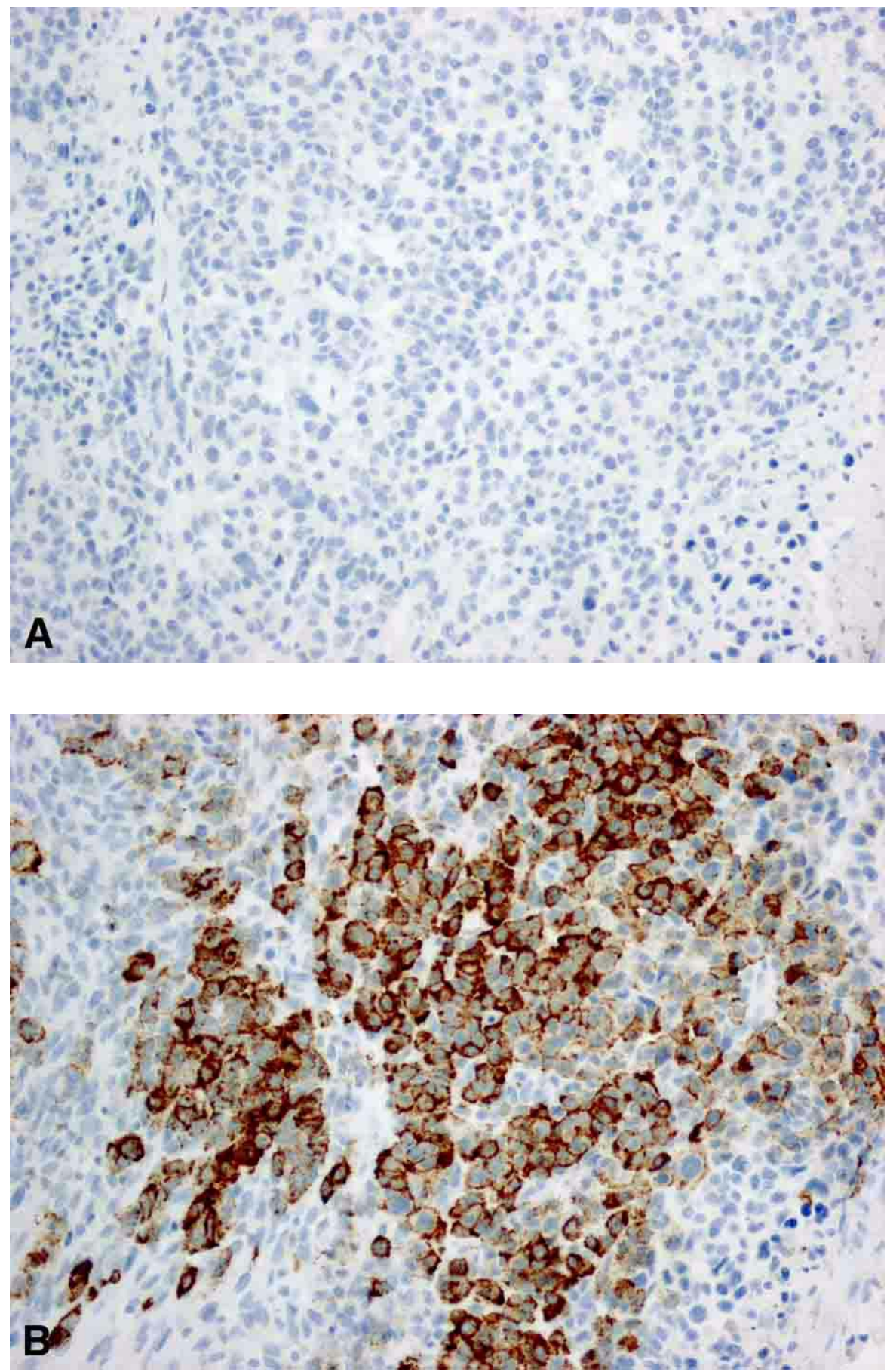

Fig. 4. Comparison of the conventional dextran-polymer method and CSA method on the immunostaining with phosphorylated HER1 (EGFR) in NSCLC. The phosphylated HER1 (EGFR) immunostaining was performed on an autostainer using the dextran-polymer (A) and CSA methods (B) after the heat-induced antigen retrieval with Tris-EDTA solution. The phosporylated sites EGFR in NSCLC were strongly visualized by the CSA method (B), whereas only a few tiny signals were presented by the conventional method (A).

(EGFR) TKI is not as straightforward as demonstrated by the results of preclinical data due to the complex nature of HER1 (EGFR) TK activation as well as lack of a standardized assay for measuring HER1 (EGFR) TK levels or activity in tumors. Recently, several reports have associated somatic mutations in the TK domain of EGFR in a subset of
NSCLC with sensitivity of the tumors to Iressa, suggesting that EGFR mutations may define a subset of tumors that are highly dependent on activated EGFR signaling and responsive to HER1 (EGFR) TKI therapy [27, 29]. However, there has been a report that presented Iressa-responsive patients as lacking EGFR mutations, indicating that the EGFR 
mutations are not necessary for patients to have clinical benefit from HER1 (EGFR) TKI therapy [33]. Therefore, further investigations are necessary to identify useful clinical or diagnostic predictors of responsiveness to EGFRTKIs. Some studies are needed to compare the level of phosphorylated, activated EGFR with tumor response rather than the EGFR level.

An immunohistochemical assay that works on archived tumor tissues will be strongly in demand for phosphorylated EGFR identification, considering its acceptability and convenience in routine clinical practice or research. In order to visualize phosphorylated EGFR in the tumor tissues, the assay must be sensitive enough to detect each phosphorylatedtyrosine residues in EGFR molecule. In archived FFPE tissues, in general, the antigenicity of small peptides or epitopes tends to be remarkably reduced because the fixative destroys their structure or masks the limited binding sites for antibodies via cross-linking action of formalin [14]. Thus, it may be difficult to detect the epitopes that may be very sensitive to formalin fixation by conventional IHC methods such as streptavidin-biotin complex (ABC) method or dextran-polymer method. The enzymatic or heat-induced antigen retrieval methods may restore the antigenicity of the epitope structures modified by formalin, and heat-induced antigen retrieval has been used successfully to detect a wide variety of antigens in FFPE tissues [31]. Although the underlying mechanism of the heat-induced antigen retrieval remains unclear, it is necessary to understand the factors that influence its effectiveness. Recent studies indicate that a combination of high-temperature heating and calcium-chelating are involved in the antigen unmasking [6, 25]. It is suggested that calcium complex formation with proteins in FFPE tissues may mask epitopes, and that pre-treatment by means of heating with calcium chelating solutions, such as citrate buffer ( $\mathrm{pH}$ 6.0) or TrisEDTA solution ( $\mathrm{pH} 9.0)$, extract the calcium ions from the calcium-protein complex, resulting in unmasking the epitopes. The Tris-EDTA solution, which has a stronger chelating property, tends to produce more profound antigen retrieval. The heat-induced antigen retrieval is regarded as an easy heating technique. However, it plays a very important role in equalizing and emphasizing the intensity of immunohistochemical signals, especially those derived from phosphorylation of EGFR molecules.

In addition to an effective antigen retrieval method, a highly sensitive detection system needs to be employed for the phosphorylated EGFR identification. A catalyzed signal amplification (CSA) method using hapten-labeled tyramide has been introduced for solid-phase assays, and has subsequently been adapted for IHC and ISH assays [18, 55]. The CSA technique is based on oxidization reaction of tyramide induced by peroxidase in the presence of hydrogen peroxidase, and allows a 500- to 1,000-fold increase in sensitivity of IHC signals when compared with the conventional methods (Fig. 4). An optimal antigen retrieval method prior to the signal amplification is much more critical to maximize availability of the phosphorylated sites of EGFR as well as high resolution (Fig. 4B).

Although the general principle of the CSA is simple, its practical complexity has revealed poor amplification efficiency and reproducibility as well as target localization [7, 18]. Additionally, using the CSA method after the intensive heat-induced antigen retrieval, the background staining may amplify as well without higher stringent washing buffer that contains higher saline and non-ionic detergent. Recently, the use of automated immunostaining assay with a variety of detection systems has brought about high productivity, quality assurance, and reproducible results without background staining in diagnostic pathology [14]. Likewise, the CSA method can be applied to the autostainer to perform the time-consuming and complicated amplification technique with minimal effort in an accurate, consistent, and reproducible manner [7]. An optimal combination of the heat-induced antigen retrieval with EDTA-based solutions, CSA, and automation approaches will be needed to achieve the development of an ideal pharmDx test for the phosphorylated, activated EGFR identification.

Several clinical studies with EGFR-TKIs have been initiated to measure expression and activation of EGFR and other downstream signaling molecules such as PI3K, Akt, and MAPK and their phosphorylation in tumor tissues [6, 25]. The objective of those studies is to establish a profile of potential responders to TKIs. IHC diagnostic tests for molecular targeted therapies, pharmDx tests that are able to assess expression levels, and phosphorylation/activation of various signaling molecules will be valuable in defining subsets of patients who may potentially response to the molecular targeted therapies.

\section{References}

1. Adam, J. C. (1992) Biotin amplification of biotin and horseradish peroxidase signals in histochemical stains. J. Histochem. Cytochem. 40; 1457-1463.

2. Anido, J., Matar, P., Albanell, J., Guzman, M., Rojo, F., Arribas, J., Averbuch, S. and Baselga, J. (2003) ZD1839, a specific epidermal growth factor receptor (EGFR) tyrosine kinase inhibitor, induces the formation of inactive EGFR/HER2 and EGFR/HER3 heterodimers and prevents heregulin signaling in HER2-overexpressing breast cancer cells. Clin. Cancer Res. 9; 1274-1283.

3. Arteaga, C. L. (2002) Overview of epidermal growth factor receptor biology and its role as a therapeutic target in human neoplasia. Semin. Oncol. 29 (5 Suppl 14); 3-9.

4. Baselga, J., Norton, L., Albanell, J., Kim, Y. M. and Mendelsohn, J. (1998) Recombinant humanized anti-HER2 antibody $\left(\right.$ Herceptin $^{\mathrm{TM}}$ ) enhances the antitumor activity of paclitaxel and doxorubicin against HER2/neu overexpressing human breast cancer xenografts. Cancer Res. 58; 2825-2831.

5. Baselga, J. and Albanell, J. (2002) Targeting epidermal growth factor receptor in lung cancer. Curr. Oncol. Rep. 4; 317-324.

6. Brognard, J., Clark, A. S., Ni, Y. and Dennis, P. A. (2001) Akt/ protein kinase $\mathrm{B}$ is constitutively active in non-small cell lung cancer cells and promotes cellular survival and resistance to chemotherapy and radiation. Cancer Res. 61; 3986-3997.

7. Bussolati, G., Gugliotta, P., Volante, M., Pace, M. and Papotti, M. (1997) Retrieved endogenous biotin: a novel marker and a potential pitfall in diagnostic immunohistochemistry. Histo- 
pathology 31; 400-407.

8. Carpenter, G. and Cohen, S. (1990) Epidermal growth factor. J. Biol. Chem. 265; 7709-7712.

9. Ciardiello, F. and Tortora, G. (2001) A novel approach in the treatment of cancer: targeting the epidermal growth factor receptor. Clin. Cancer Res. 7; 2958-2970.

10. Demetri, G. D., von Mehren, M., Blanke, C. D., Van den Abbeele, A. D., Eisenberg, B., Roberts, P. J., Heinrich, M. C., Tuveson, D. A., Singer, S., Janicek, M., Fletcher, J. A., Silverman, S. G., Silberman, S. L., Capdeville, R., Kiese, B., Peng, B., Dimitrijevic, S., Druker, B. J., Corless, C., Fletcher, C. D. and Joensuu, H. (2002) Efficacy and safety of imatinib mesylate in advanced gastrointestinal stromal tumors. N. Engl. J. Med. 347; 472-480.

11. Druker, B. J. (2001) Chronic myeloid leukemia. Sceptical scientists. Lancet 358 (suppl); S11.

12. Druker, B. J., Sawyers, C. L., Kantarjian, H., Resta, D. J., Reese, S. F., Ford, J. M., Capdeville, R. and Talpaz, M. (2001) Activity of a specific inhibitor of the BCR-ABL tyrosine kinase in the blast crisis of chronic myeloid leukemia and acute lymphoblastic leukemia with the Philadelphia chromosome. N. Engl. J. Med. 344; 1038-1042.

13. Ebert, A. D., Wechselberger, C., Martinez-Lacaci, I., Bianco, C., Weitzel, H. K. and Salomon, D. S. (2000) Expression and function of EGF-related peptides and their receptors in gynecological cancer-from basic science to therapy. J. Recept. Signal Transduct. Res. 20; 1-46.

14. Fox, C. H., Johnson, F. B., Whiting, J. and Roller, P. P. (1985) Formaldehyde fixation. J. Histochem. Cytochem. 33; 845-853.

15. Fukuoka, M., Yano, S., Giaccone, G., Tamura, T., Nakagawa, K., Douillard, J. Y., Nishiwaki, Y., Vansteenkiste, J., Kudoh, S., Rischin, D., Eek, R., Horai, T., Noda, K., Takata, I., Smit, E., Averbuch, S., Macleod, A., Feyereislova, A., Dong, R. P. and Baselga, J. (2003) Multi-institutional randomized phase II trial of gefitinib for previously treated patients with advanced non-smallcell lung cancer. J. Clin. Oncol. 21; 2237-2246.

16. Giaccone, G., Herbst, R. S., Manegold, C., Scagliotti, G., Rosell, R., Miller, V., Natale, R. B., Schiller, J. H., Von Pawel, J., Pluzanska, A., Gatzemeier, U., Grous, J., Ochs, J. S., Averbuch, S. D., Wolf, M. K., Rennie, P., Fandi, A. and Johnson, D. H. (2004) Gefitinib in combination with gemcitabine and cisplatin in advanced non-small-cell lung cancer: a phase III trial-INTACT 1. J. Clin. Oncol. 22; 777-784.

17. Goldstein, N. S. and Armin, M. (2001) Epidermal growth factor receptor immunohistochemical reactivity in patients with American Joint Committee on cancer stage IV colon adenocarcinoma: implications for a standardized scoring system. Cancer 92; 13311346.

18. Hashizume, K., Hatanaka, Y., Kamihara, Y. and Tani, Y. (2001) Automated immunohistochemical staining of formalin-fixed and paraffin-embedded tissues using a catalyzed signal amplification method. Appl. Immunohistochem. Mol. Morphol. 9; 54-60.

19. Hatanaka, Y., Hashizume, K., Kamihara, Y., Itoh, H., Tsuda, H., Osamura, R. Y. and Tani, Y. (2001) Quantitative immunohistochemical evaluation of HER2/neu expression with HercepTest ${ }^{\mathrm{TM}}$ in breast carcinoma by image analysis. Pathol. Int. 51; 33-36.

20. Herbst, R. S., Maddox, A. M., Rothenberg, M. L., Small, E. J., Rubin, E. H., Baselga, J., Rojo, F., Hong, W. K., Swaisland, H., Averbuch, S. D., Ochs, J. and LoRusso, P. M. (2002) Selective oral epidermal growth factor receptor tyrosine kinase inhibitor ZD1839 is generally well-tolerated and has activity in non-smallcell lung cancer and other solid tumors: results of a phase I trial. J. Clin. Oncol. 20; 3815-3825.

21. Herbst, R. S., Giaccone, G., Schiller, J. H., Natale, R. B., Miller, V., Manegold, C., Scagliotti, G., Rosell, R., Oliff, I., Reeves, J. A., Wolf, M. K., Krebs, A. D., Averbuch, S. D., Ochs, J. S.,
Grous, J., Fandi, A. and Johnson, D. H. (2004) Gefitinib in combination with paclitaxel and carboplatin in advanced non-smallcell lung cancer: a phase III trial-INTACT 2. J. Clin. Oncol. 22; 785-794.

22. Kaelin, W. G. Jr. (2004) Gleevec: prototype or outlier? Sci. STKE 225; pe12.

23. Kitamura, Y., Hirota, S. and Nishida, T. (2003) Gastrointestinal stromal tumors (GIST): a model for molecule-based diagnosis and treatment of solid tumors. Cancer Sci. 94; 315-320.

24. Koretz, K., Schlag, P. and Moller, P. (1990) Expression of epidermal growth factor receptor in normal colorectal mucosa, adenoma, and carcinoma. Virchows Arch. A. Pathol. Anat. Histopathol. 416; 343-349.

25. Lee, S. H., Kim, H. S., Park, W. S., Kim, S. Y., Lee, K. Y., Kim, S. H., Lee, J. Y. and Yoo, N. J. (2002) Non-small cell lung cancer frequently express phosphorylated Akt; an immunohistochemical study. APMIS 110; 587-592.

26. Levitzki, A. and Gazit, A. (1995) Tyrosine kinase inhibition: an approach to drug development. Science 267; 1782-1788.

27. Lynch, T. J., Bell, D. W., Sordella, R., Gurubhagavatula, S., Okimoto, R. A., Brannigan, B. W., Harris, P. L., Haserlat, S. M., Supko, J. G., Haluska, F. G., Louis, D. N., Christiani, D. C., Settleman, J. and Haber, D. A. (2004) Activating mutations in the epidermal growth factor receptor underlying responsiveness of non-small-cell lung cancer to gefitinib. N. Engl. J. Med. 350; 2129-2139.

28. Maia, D. M. (1999) Immunohistochemical assays for HER2 overexpression. J. Clin. Oncol. 17; 1650.

29. Miller, V. A., Kris, M. G., Shah, N., Patel, J., Azzoli, C., Gomez, J., Krug, L. M., Pao, W., Rizvi, N., Pizzo, B., Tyson, L., Venkatraman, E., Ben-Porat, L., Memoli, N., Zakowski, M., Rusch, V. and Heelan, R. T. (2004) Bronchioloalveolar pathologic subtype and smoking history predict sensitivity to gefitinib in advanced non-small-cell lung cancer. J. Clin. Oncol. 22; 11031109.

30. Morgan, J. M., Navabi, H., Schmid, K. W. and Jasani, B. (1994) Possible role of tissue-bound calcium ions in citrate-mediated high-temperature antigen retrieval. J. Pathol. 174; 301-307.

31. Myers, J. A., Mehta, P. and Hunter, A. W. (1995) Automated double-label: immunohistochemistry. J. Surg. Pathol. 1; 105113.

32. Nicholson, R. I., Gee, J. M. and Harper, M. E. (2001) EGFR and cancer prognosis. Eur. J. Cancer 37 (suppl 4); S9-S15.

33. Paez, J. G., Janne, P. A., Lee, J. C., Tracy, S., Greulich, H., Gabriel, S., Herman, P., Kaye, F. J., Lindeman, N., Boggon, T. J., Naoki, K., Sasaki, H., Fujii, Y., Eck, M. J., Sellers, W. R., Johnson, B. E. and Meyerson, M. (2004) EGFR mutations in lung cancer: correlation with clinical response to gefitinib therapy. Science 304; 1497-1500.

34. Perez-Soler, R., Chachoua, A. and Huberman, M. (2001) A phase II trial of the epidermal growth factor receptor (EGFR) tyrosine kinase inhibitor OSI-774, following platinum-based chemotherapy, in patients (pts) with advanced, EGFR-expressing, non-small cell lung cancer (NSCLS). Proc. Am. Soc. Clin. Oncol. 20;310a.

35. Prenzel, N., Fischer, O. M., Streit, S., Hart, S. and Ullrich, A. (2001) The epidermal growth factor receptor family as a central element for cellular signal transduction and diversification. Endocr. Relat. Cancer 8; 11-31.

36. Salomon, D. and Gullick, W. (2001) The erbB family of receptors and their ligands: multiple targets for therapy. Signal 2; 4-11.

37. Salomon, D. S., Brandt, R., Ciardiello, F. and Normanno, N. (1995) Epidermal growth factor-related peptides and their receptors in human malignancies. Crit. Rev. Oncol. Hematol. 19; 183232.

38. Schlessinger, J. (2000) Cell signaling by receptor tyrosine kinases. Cell 103; 211-225. 
39. Sedlacek, H. H. (2000) Kinase inhibitors in cancer therapy: a look ahead. Drugs 59; 435-476.

40. Shi, S. R., Chaiwun, B., Young, L., Cote, R. J. and Taylor, C. R. (1993) Antigen retrieval technique utilizing citrate buffer or urea solution for immunohistochemical demonstration of androgen receptor in formalin-fixed paraffin sections. J. Histochem. Cytochem. 41; 1599-1604.

41. Shi, S. R., Cote, R. J. and Taylor, C. R. (2001) Antigen retrieval techniques: current perspectives. J. Histochem. Cytochem. 49; 931-937.

42. Shimizu, C., Hasegawa, T., Tani, Y., Takahashi, F., Takeuchi, M., Watanabe, T., Ando, M., Katsumata, N. and Fujiwara, Y. (2004) Expression of Insulin-like growth factor 1 receptor in primary breast cancer: immunohistochemical analysis. Hum. Pathol. $35 ; 1537-1542$.

43. Slamon, D. J., Leyland-Jones, B., Shak, S., Fuchs, H., Paton, V., Bajamonde, A., Fleming, T., Eiermann, W., Wolter, J., Pegram, M., Baselga, J. and Norton, L. (2001) Use of chemotherapy plus a monoclonal antibody against HER2 for metastatic breast cancer that overexpresses HER2. N. Engl. J. Med. 344; 783-792.

44. Slichenmyer, W. J. and Fry, D. W. (2001) Anticancer therapy targeting the erbB family of receptor tyrosin kinases. Semin. Oncol. 28 (suppl 16); 67-79.

45. Tani, Y. (1999) PCR in situ amplification and catalyzed signal amplification: approaches of higher sensitive, non-radioactive in situ hybridization. Acta Histochem. Cytochem. 32; 261-270.

46. Tani, Y. (2000) Molecular analysis and therapeutic application; molecular targeting for breast cancer treatment. Acta Histochem. Cytochem. 33; 185-188.

47. Tsuda, H., Tani, Y., Hasegawa, T. and Fukutomi, T. (2001) Con- cordance in judgments among c-erbB-2 (HER2/neu) overexpression detected by two immunohistochemical tests and gene amplification detected by southern blot hybridization in breast carcinoma. Pathol. Int. 51; 26-32.

48. Vogel, C. L., Cobleigh, M. A., Tripathy, D., Gutheil, J. C., Harris, L. N., Fehrenbacher, L., Slamon, D. J., Murphy, M., Novotny, W. F., Burchmore, M., Shak, S., Stewart, S. J. and Press, M. (2002) Efficacy and safety of trastuzumab as a single agent in first-line treatment of HER2-overexpressing metastatic breast cancer. $J$. Clin. Oncol. 20; 719-726.

49. Wahl, M. I. and Carpenter, G. (1987) Role of growth factors and their receptors in the control of normal cell proliferation and cancer. Clin. Physiol. Biochem. 5; 130-139.

50. Weiner, L. M. (1999) An overview of monoclonal antibody therapy of cancer. Semin. Oncol. 26; 41-50.

51. Wells, A. (1999) EGFR receptor. Int. J. Biochem. Cell Biol. 31; 637-643.

52. Wisecarver, J. L. (1999) HER-2/neu testing comes of age. Am. J. Clin. Pathol. 111; 299-301.

53. Woodburn, J. R. (1999) The epidermal growth factor receptor and its inhibition in cancer therapy. Pharmacol. Ther. 82; 241-250.

54. Yasui, W., Sumiyoshi, H., Hata, J., Kameda, T., Ochiai, A., Ito, H. and Tahara, E. (1988) Expression of epidermal growth factor receptor in human gastric and colonic carcinomas. Cancer Res. $48 ; 137-141$.

55. Zhang, H., Li, Y., Peng, T., Aasa, M., Zhang, L., Yang, Y. and Archard, L. C. (2000) Localization of enteroviral antigen in myocardium and other tissues from patients with heart muscle disease by an improved immunohistochemical techniques. J. Histochem. Cytochem. 48; 579-584. 